\title{
Rising wages, mechanization, and the substitution between capital and labor: evidence from small scale farm system in China
}

\author{
Xiaobing Wang ${ }^{\mathrm{a}, \mathrm{b}}$, Futoshi Yamauchic ${ }^{\mathrm{c}}$, Jikun Huanga,b,* \\ ${ }^{a}$ Center for Chinese Agricultural Policy, School of Advanced Agriculture, Peking University, Yiheyuan Road No. 5, Haidian District, Beijing 100871, China \\ ${ }^{\mathrm{b}}$ Center for Chinese Agricultural Policy, Institute of Geographic Sciences and Natural Resources Research, Chinese Academy of Sciences, Datun road No.11a, \\ Chaoyang District, Beijing 100101, China \\ ${ }^{c}$ Development Research Group, World Bank, 1818 H St., NW Washington, DC 20433, USA
}

Received 23 December 2014; received in revised form 9 September 2015; accepted 23 December 2015

\begin{abstract}
This article aims to investigate major factors that led to the observed pace of mechanization and the substitution between labor and machines in rural China. We used commodity-wise province-level panel data for more than a quarter of a century from 1984 to 2012 . The analysis demonstrated a dramatic increase in real agricultural wages in recent years, especially after 2003 , in contrast to a relatively stable real machine price. The relative price of machines against agricultural labor has declined in an accelerating way, which contributed to the observed rapid introduction of machines. The elasticity of substitution between labor and machines was large in some commodities, which contributed to a fast substitution of labor by machines.
\end{abstract}

JEL classifications: J31, Q16

Keywords: Wage growth; Labor; Mechanization; Crops; China

\section{Introduction}

It has been increasingly recognized in recent years that Asian agriculture, facing rapidly rising real wages driven by labor shortage, is under a serious pressure to need a substitution of labor by machines, that is, labor-saving technology. China is not an exception. As a result of its fast urbanization, labor shortage has been increasingly serious in Chinese agriculture. It is well documented that, in some areas, farmers started expanding their operational land and relying more heavily on machine services in response to rising real wages (Wang et al., 2014). Thus, mechanization is certainly taking in place. Since more labor is increasingly absorbed into nonagricultural sectors, the substitution of labor by machines plays a central role in sustaining agricultural production in China.

China's agriculture is uniquely characterized by an extremely egalitarian distribution of cultivated land. There are more than 200 million rural households with the average holding of around

\footnotetext{
*Corresponding author. Tel.: +0086-10-64889440; fax: +0086-1064856533. E-mail address: jkhuang.ccap@pku.edu.cn (X. Wang).

Data Appendix Available Online

A data appendix to replicate main results is available in the online version of this article.
}

0.60 hectares (NSBC, 2014). The egalitarian distribution of cultivated land has contributed significantly to food security in China (Lin, 1992). More recently, however, the government has attempted to give small farmers incentives to search for new ways to improve the efficiency of their input and resource utilizations, such as land consolidations in recent years.

China has witnessed agricultural mechanization and labor mobility in the past two decades. After household's responsibility system was introduced, mechanization shrank significantly as surplus labor existed in agriculture and mechanical operations were stagnated for one decade (Lin, 1992; Cook, 1999). However, the rapid expansion of employment opportunities in nonagricultural sectors has changed the situation. It has increased the speed of mechanization over the past two decades or so (Ji et al., 2012; Yang et al., 2013; Wang et al., 2014). The National Statistics also shows that both the area of land cultivated and that of land harvested by machines increased by $4 \%$ and $9 \%$ annually from 1990 to 2012, respectively (NSBC, 2013).

In this article, we use commodity-wise province-level panel data to investigate major factors that led to the observed pace of mechanization and to confirm the substitution between labor and machines. In the first exercise, we focus on the roles of 


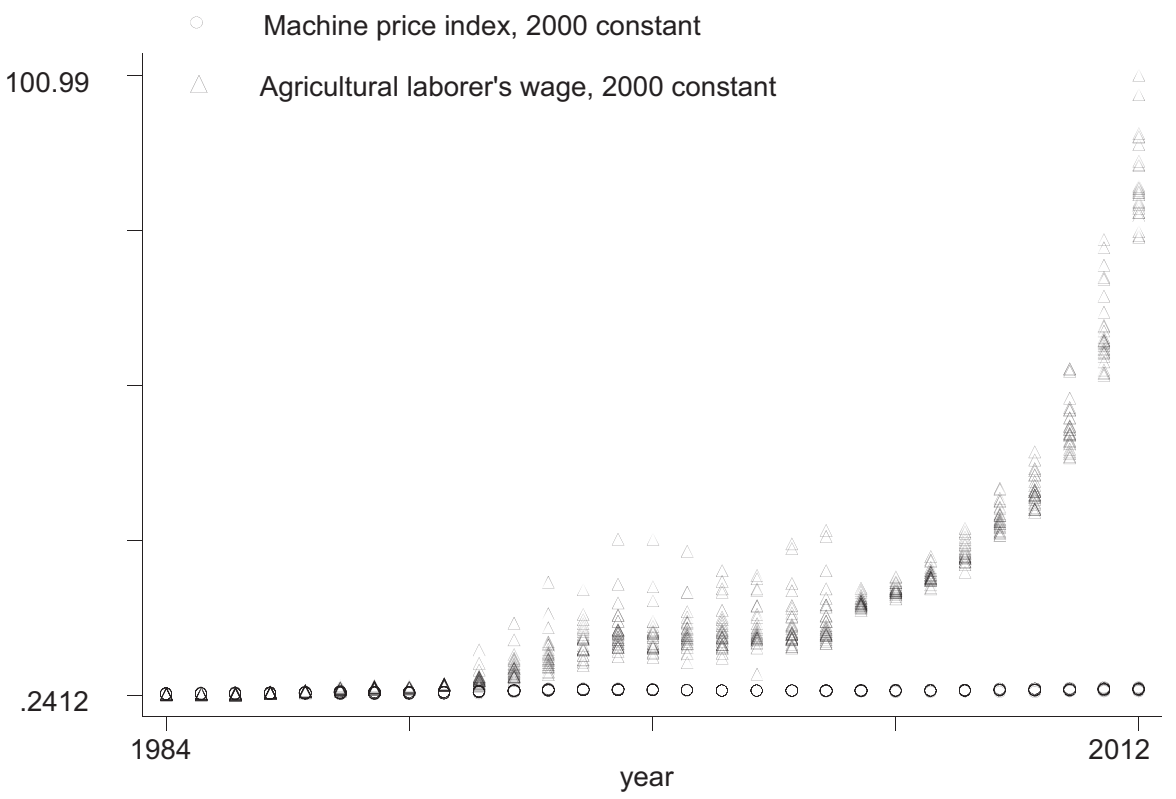

Fig. 1. Agricultural wage and machine price.

(changes in) factor prices. The article contributes to the existing literature in two ways. First, the unique dataset of production cost across crops enables us to compare estimation results across major crops and identify the patterns. Second, the relatively long panel data from the period of large structural transformation in China offer relativelylarge time-series variations in factor prices, especially wages, along with the accelerating process of urbanization (labor shortage in agriculture).

The key idea of this article is related to the induced innovations proposed by Hicks (1932), and later elaborated by Hayami and Ruttan (1985), who introduced the idea of induced institutional changes in agriculture. That is, relative prices dictate the direction of technical change. An increase in real wages may induce a technical change to save labor, that is, mechanization, but also could lead to a new institutional arrangement that saves labor and/or reduces users' costs of machines on farm even without land consolidation. For example, if machines can be rented relatively cheaply or the supply of machine services by professional providers is available without additional transaction costs, small farmers may be able to effectively save labor by utilizing machine services or directly using machines through rental markets. ${ }^{1}$

We observe a rapid increase in real agricultural wages in recent years (especially, after 2003), while real machine price remained relatively stable. Thus, the relative price of machines against agricultural labor has declined in an accelerating way, which is consistent with the observed rapid introduction of machines (or use of machine services). Interestingly, our analysis also shows that the contribution of changes in the relative price is equally important across major crops.

\footnotetext{
${ }^{1}$ More detailed discussion of the supply of machine services in China could be found in Ji et al. (2012) and Wang et al. (2014).
}

In the second exercise, we estimate production frontier functions to examine the substitutability between labor and machines for different crops with the special concern on the role of farm size in determining technical efficiency. Consistent with findings from the first exercise, our estimates of the elasticity of substitution between labor and machines suggest that the capital-labor substitution has been important in many crops to promote mechanization, especially in recent years as real wages increased rapidly.

\section{Wage and mechanization in China}

\subsection{Data}

We use data collected every year for more than a quarter of a century from 1984 to 2012 at provincial level by the State Price Bureau (SPB), the State Development and Planning Commission. Using a sample of more than 20,000 households, data were collected to capture the per-mu production costs of all of China's major crops. ${ }^{2}$ The data contain information on quantities and total expenditures of all major inputs including expenses on machine and labor. In the last several years, the data have been published by the SPB, the State Development and Planning Commission (The Compiled Materials of Costs and Profits of Agricultural Products of China, 1988-2013). Previously, the data have been used in analyses on China's agricultural supply and input demand (Huang and Rozelle, 1996; Huang et al., 1999; Jin et al., 2002, 2010; Rae et al., 2006).

In this study, we examine the record of mechanization for China's most important crops. To do so, we withdrew the cost

\footnotetext{
${ }^{2} 1$ hectare $=15 \mathrm{mu}$
} 


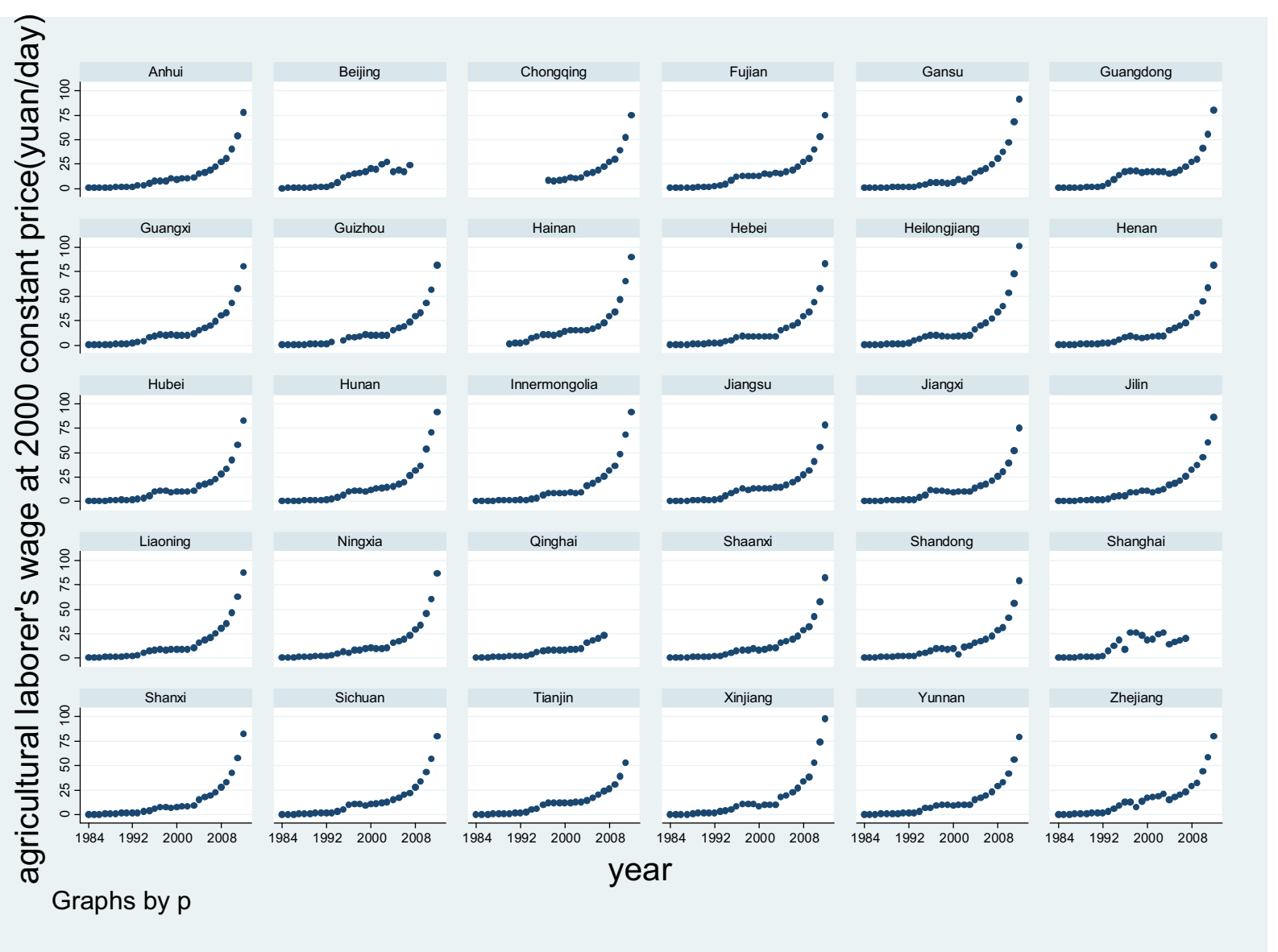

Fig. 2. The trend of agricultural laborer's wage at 2000 constant price (Yuan/day) by province, 1984-2012.

records on six crops: wheat, corn, Japonica rice, cotton, soybean, and rapeseeds. The included crops contribute to nearly $60 \%$ of sown areas of crops in $2012 .^{3}$

We also combined the data collected from other sources (at provincial level, 1984-2012). Farm size is calculated by the land per capita times the number of permanent rural-family residents obtained from China Yearbook of Rural Household Survey (NSBC, 1985-2013). Machine price index is obtained from China's Statistics Yearbooks (NSBC, 1985-2013). All of the value terms in this study are presented at the year of 2000 constant price.

\subsection{Relative price of machines and labor and machine use}

The published statistics do not directly provide a record of agricultural wage. To fill the gap, we calculate the agricultural

\footnotetext{
${ }^{3}$ The other crops are peanut, sugarcane, sugar beat, sesame, flaxseed, sunflower, tobacco, fiber crops, Chinese medicine and vegetables. These crops are produced in a few provinces, and thus the number of observations is not large enough for estimation. It is also difficult to compare yields across commodities categorized in "other crops." The crops used in our analysis have kept their aggregated share in the total production between $65 \%$ and $70 \%$ throughout the period from 1984 to 2012.
}

wage by adding all of the labor cost and the working days across the crops for each province between 1984 and 2012. This is to reflect the daily wage foregone by farmers who work in cropping. A potential caveat is that since the family labor and hired labor are aggregated, the above method masks the substitution between family labor and hired labor. ${ }^{4}$ Overall, agricultural wage remained comparatively low, being less than 1.5 US\$/day for two decades, but started rapidly increasing since 2003 (shown in Fig. 1). Agricultural wages increased a little more than seven times from 0.20 US\$/day in 1984 to 1.48 US\$/day in 2003. From 2003 to 2012, it increased around 9 times reaching $13.11 \mathrm{US} \$ /$ day, with an accelerating annual growth rate. ${ }^{5}$ Figure 2 shows changes in agricultural wages by province. Though some differences are observed across

\footnotetext{
${ }^{4}$ The commodity-wise production cost and revenue data only record the number of working days of agricultural labor in each commodity.

${ }^{5}$ We also obtain the wage in the collective enterprises. We choose the wage in the collective enterprises rather than state-own enterprises because migrants are only rarely employed in the state-owned enterprises. The collective enterprise wage increased only a little more than 2.5 times in the past three decades from around 1384 US\$/year in 1984 to 3600 US\$/year in 2012. However, it is observed that the collective enterprise wage also increased at an accelerating rate (around 13\% per year) since 2003. The results in the machine use equation are qualitatively the same.
} 

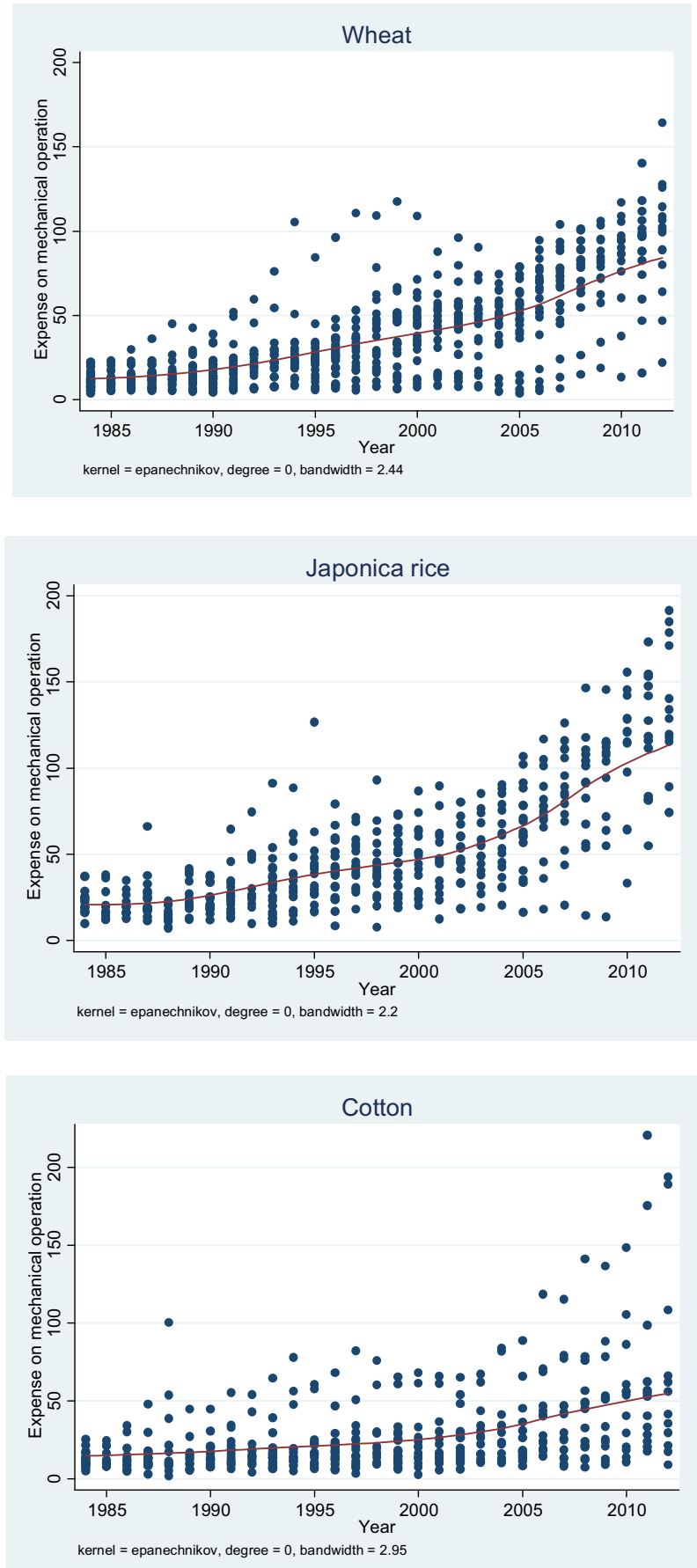
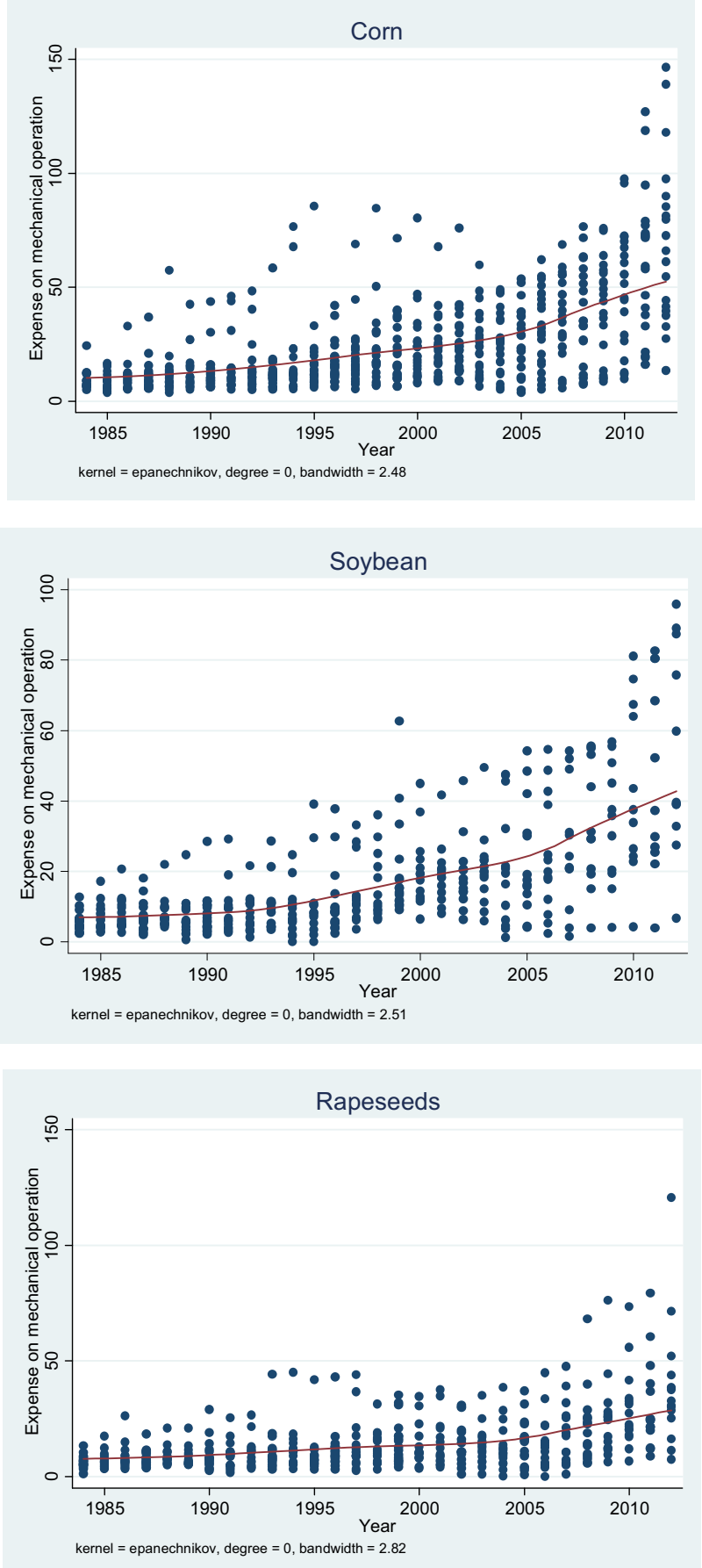

Fig. 3. The evolution of expense on mechanical operation by crops at 2000 constant price (Yuan/mu), 1984-2012.

provinces, we confirm that wages increased dramatically in recent years in many provinces.

The machine price is represented by the retail price index of machines. The price index of machine is a weighted arithmetic average, where the weights are constructed from actual quantities purchased. As shown in Fig. 1, the machine price remains surprisingly stable over time, which shows a sharp contrast to the behavior of agricultural wages.
The use of machines is proxied by expenses on machine use in production deflated and normalized at 2000 constant price. Overall, there appears to be an increase in machine use in all of the crops considered, however, the rate of increase differs across the crops (Fig. 3). The use of machines has increased fast in wheat, corn, and soybean productions but only at moderate rate in cotton. The heterogeneity in machine use across crops comes from crop traits. For example, the production of some crops such 

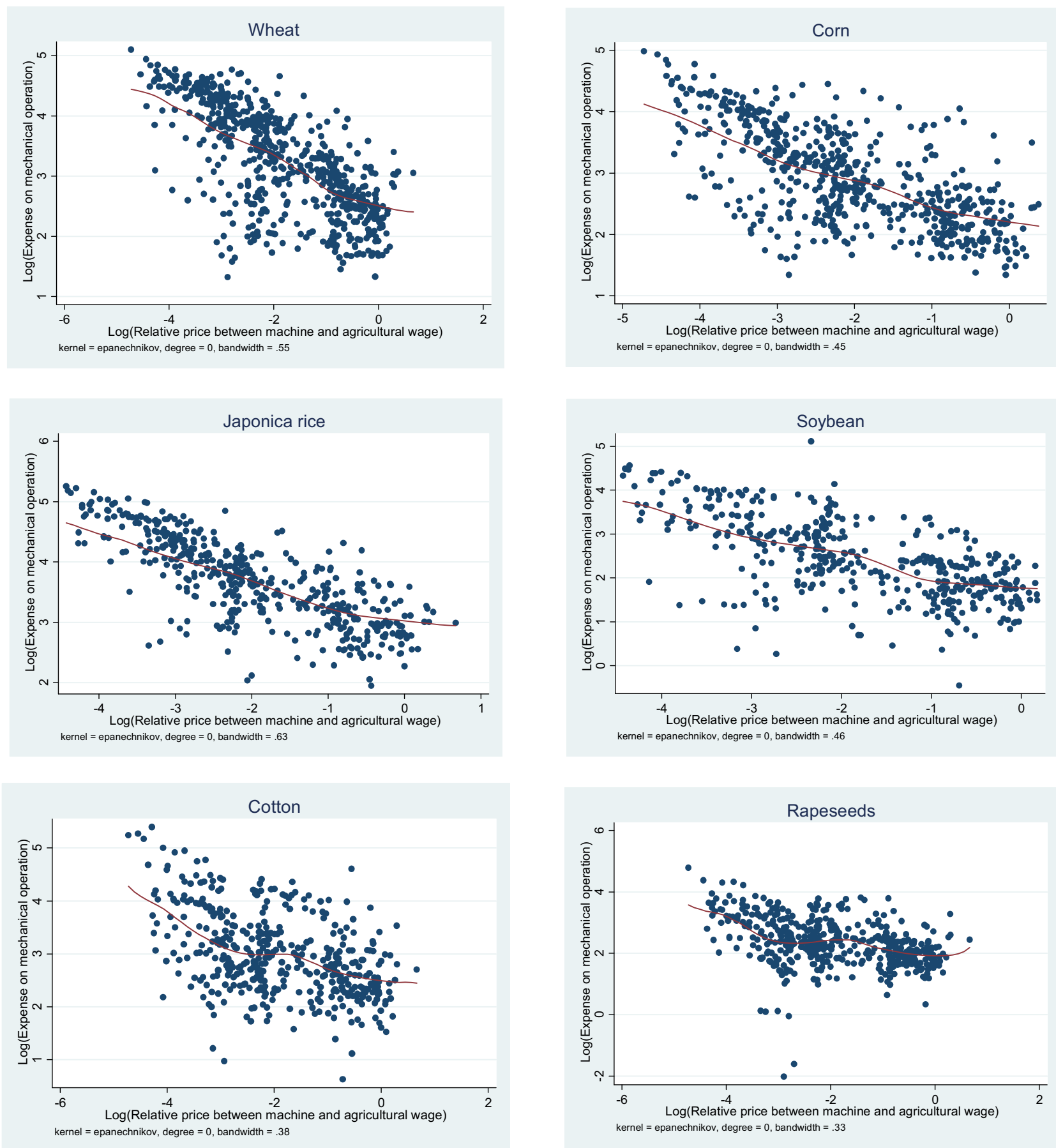

Fig. 4. Relative price and machine use by crops.

as wheat and corn could be largely mechanized, while others including cotton and soybean, especially in harvest seasons, still need labor intensively.

Figure 4 show the relationship between the relative price of machines to agricultural labor and the use of machines (per mu). Quite strikingly, the use of machines in each crop is clearly negatively correlated with the relative price of machines to agricultural labor. From Fig. 1, we know that the relative price has declined dramatically in recent years, and therefore, can conclude that the decline of the relative price seems to significantly explain the expansion of mechanization in major crops in China. The empirical results are consistent with the above descriptive finding. Table 1 shows the effect of the relative price on machine use. In three major commodities, we confirm that the relative price and machine use are significantly negatively related controlling for province fixed effects.

Finally, we show changes in the average farm size by province (Fig. 5). Though the national trend seems to be downward, some 


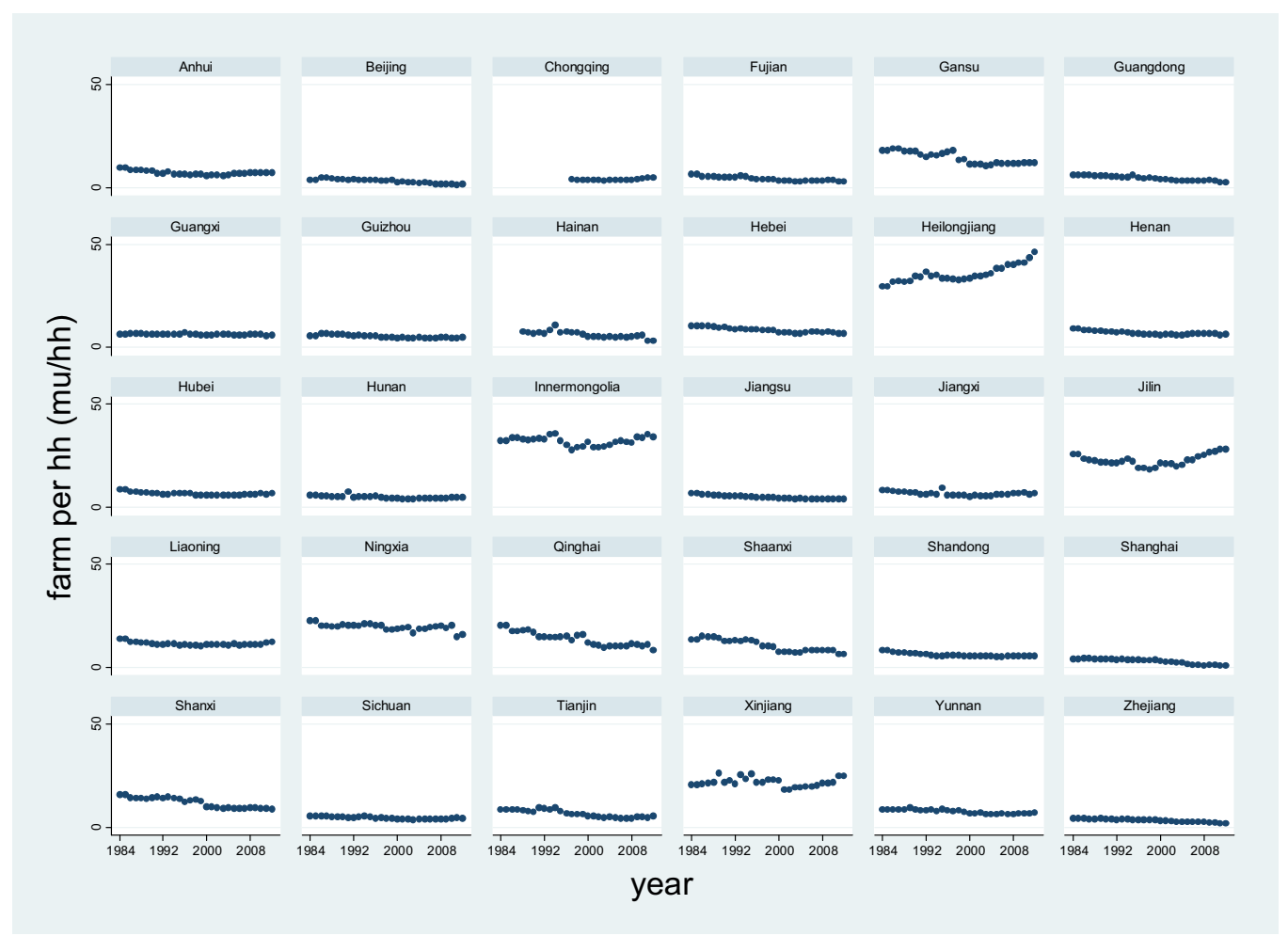

Fig. 5. The trend of farm size (mu/hh) by province, 1984-2012.

Table 1

Estimation of expense on mechanical operation by crops

\begin{tabular}{|c|c|c|c|c|c|c|}
\hline & Wheat & Corn & Japonica rice & Soybean & Cotton & Rapeseeds \\
\hline Relative price & $\begin{array}{l}-0.1520^{* *} \\
(2.09)\end{array}$ & $\begin{array}{c}-0.4024^{* * * *} \\
(4.44)\end{array}$ & $\begin{array}{l}-0.3352^{* * *} \\
(5.22)\end{array}$ & $\begin{array}{c}-0.1284 \\
(1.10)\end{array}$ & $\begin{array}{l}0.0228 \\
(0.15)\end{array}$ & $\begin{array}{c}-0.0055 \\
(0.06)\end{array}$ \\
\hline \multicolumn{7}{|c|}{ Time, time squared and Province fixed effect are included } \\
\hline$R^{2}$ & 0.804 & 0.743 & 0.797 & 0.563 & 0.390 & 0.286 \\
\hline No. of obs. & 625 & 596 & 439 & 406 & 430 & 456 \\
\hline
\end{tabular}

Note: Absolute $t$-statistics in parentheses; ${ }^{*} P<0.10,{ }^{* *} P<0.05,{ }^{* * *} P<0.01$.

provinces reversed the trend and experienced an increase in the average farm size. Note that we do not have crop-wise data on farm size, which creates measurement errors in this variable and possibly the associated attenuation bias. ${ }^{6}$

\section{Method}

In the analysis below, we aim to know (i) (potentially time varying) machine effects on yield, (ii) the degree in which labor and machines are substitutable, (iii) determinants of technical inefficiency, and (iv) potential heterogeneity in the above points

\footnotetext{
${ }^{6} \mathrm{We}$ are aware that a portion of rural population (say, farmers) do not cultivate but work in nonagriculture sectors, which creates measurement errors, potentially biasing our results on farm size in the technical efficiency function. To mitigate this issue, we take log of farm size to separate out the multiplicative measurement errors, which will be captured by province dummies under the assumption that a large portion of the variations of the errors comes from inter-province differences.
}

across crops. Drawing upon the observations on the relative price of machines and labor, we use the indicator variable which takes the value of one after 2004 (and zero otherwise) to know whether machine effects and the machine-labor substitution changed around that time.

Following Battese and Coelli (1992) and Kumbhakar et al. (2000), the stochastic and pooled production frontier model under the nonneutral technological change assumption can be written as follows:

$Q_{i t}=f\left(X_{i t}, T ; \beta\right)+v_{i t}-u_{i t}$

$\mu_{i t}=\gamma_{0}+\gamma_{1} \ln S_{i t}+\varepsilon_{i t}$,

where $Q_{i t}$ represents the yield of each crop for province $i$ in year $t, f\left(X_{i t}, T ; \beta\right)$ is a suitable production function form (translog specification in this study), $X_{i t}$ is the vector of conventional inputs including labor, machine, and chemical fertilizer, $T$ is 
Table 2

Stochastic frontier estimation of production function by crops

\begin{tabular}{|c|c|c|c|c|c|c|}
\hline & Wheat & Corn & Japonica rice & Soybean & Cotton & Rapeseeds \\
\hline \multirow[t]{2}{*}{ Labor } & $0.4177^{* * *}$ & $0.6833^{* * *}$ & $0.5776^{* * *}$ & $0.5153^{* * *}$ & $0.4880^{* * *}$ & $0.5096^{* * *}$ \\
\hline & $(18.22)$ & $(22.82)$ & (19.17) & (10.39) & (18.72) & $(7.91)$ \\
\hline \multirow[t]{2}{*}{ Machine } & $0.3985^{* * *}$ & $0.1542^{* * *}$ & $0.1851^{* * * *}$ & $0.2583^{* * * *}$ & $0.2374^{* * * *}$ & $0.1653^{\text {**** }}$ \\
\hline & (17.04) & $(8.79)$ & $(7.55)$ & $(7.86)$ & $(8.52)$ & $(3.97)$ \\
\hline \multirow[t]{2}{*}{ Chemical fertilizer } & $0.1856^{* * *}$ & $0.1413^{* * *}$ & $0.2258^{* * *}$ & $0.2199^{* * *}$ & $0.2438^{* * *}$ & $0.3005^{* * *}$ \\
\hline & $(7.15)$ & $(4.67)$ & $(8.32)$ & $(6.04)$ & $(12.52)$ & $(5.92)$ \\
\hline \multirow[t]{2}{*}{ Time } & -0.0018 & $0.0211^{* * * *}$ & $0.0115^{* * *}$ & 0.0065 & $0.0308^{* * * *}$ & $0.0246^{\text {**** }}$ \\
\hline & $(0.88)$ & $(10.00)$ & $(3.89)$ & $(1.61)$ & $(4.27)$ & $(4.42)$ \\
\hline \multirow[t]{2}{*}{ Labor $^{2}$} & 0.0664 & $-0.4005^{* * *}$ & -0.0671 & $0.2332^{*}$ & $-0.5729^{* * *}$ & 0.0373 \\
\hline & $(1.41)$ & $(6.25)$ & $(0.44)$ & $(1.75)$ & $(3.49)$ & $(0.36)$ \\
\hline \multirow[t]{2}{*}{ Machine $^{2}$} & $0.1733^{* * *}$ & $-0.1094^{* * *}$ & $0.0672^{*}$ & $0.0735^{* * *}$ & 0.0331 & $0.0379^{*}$ \\
\hline & $(3.70)$ & $(3.43)$ & $(1.73)$ & $(4.74)$ & $(0.90)$ & (1.68) \\
\hline \multirow[t]{2}{*}{ Chemical fertilizer ${ }^{2}$} & 0.0434 & 0.0181 & $0.0348^{* *}$ & $0.0563^{*}$ & $0.1968^{* * * *}$ & $0.3211^{* * * *}$ \\
\hline & $(0.85)$ & $(0.52)$ & $(2.29)$ & $(1.77)$ & $(5.88)$ & $(2.61)$ \\
\hline \multirow[t]{2}{*}{ Time $^{2}$} & $0.0007^{* *}$ & $0.0019^{* * *}$ & $-0.0017^{* * *}$ & $0.0017^{* * *}$ & $-0.0019^{* * *}$ & -0.0000 \\
\hline & $(2.26)$ & $(6.15)$ & $(3.17)$ & $(3.25)$ & $(3.94)$ & $(0.00)$ \\
\hline \multirow[t]{2}{*}{ Labor* Machine } & 0.0317 & $-0.5625^{* * *}$ & $0.6496^{* * * *}$ & 0.0779 & $0.3861^{* * *}$ & -0.0329 \\
\hline & $(0.30)$ & $(7.22)$ & $(5.30)$ & $(0.61)$ & $(2.69)$ & $(0.29)$ \\
\hline \multirow[t]{2}{*}{ Labor* Fertilizer } & $-0.2392^{* *}$ & $-0.2078^{* *}$ & $0.3655^{* *}$ & 0.0229 & $0.2277^{* *}$ & -0.0019 \\
\hline & $(2.15)$ & (2.02) & $(2.21)$ & $(0.18)$ & $(2.47)$ & $(0.01)$ \\
\hline \multirow[t]{2}{*}{ Machine $*$ Fertilizer } & 0.0872 & -0.0301 & 0.1172 & $0.1338^{* *}$ & 0.1310 & $0.2031^{* *}$ \\
\hline & $(0.83)$ & $(0.36)$ & (1.29) & $(2.31)$ & $(1.52)$ & $(2.46)$ \\
\hline \multirow[t]{2}{*}{ Labor * Time } & $-0.0171^{* * *}$ & 0.0073 & $-0.0498^{* * *}$ & 0.0026 & $-0.0534^{* * *}$ & -0.0061 \\
\hline & $(4.81)$ & (1.59) & $(7.08)$ & $(0.26)$ & $(8.54)$ & $(0.94)$ \\
\hline \multirow[t]{2}{*}{ Machine $*$ Time } & $-0.0163^{* * *}$ & $-0.0049^{* *}$ & -0.0026 & $-0.0175^{* * *}$ & $-0.0139^{* * *}$ & $-0.0103^{* * *}$ \\
\hline & $(5.61)$ & $(2.31)$ & $(0.87)$ & $(5.04)$ & $(4.45)$ & $(2.78)$ \\
\hline \multirow[t]{2}{*}{ Fertilizer $*$ Time } & 0.0019 & $0.0068^{*}$ & 0.0056 & $0.0073^{* * *}$ & $0.0244^{* * *}$ & 0.0052 \\
\hline & $(0.50)$ & (1.68) & (1.19) & $(2.73)$ & $(5.73)$ & $(0.33)$ \\
\hline \multirow[t]{2}{*}{ Constant } & $-4.8912^{* * *}$ & $-5.7304^{* * *}$ & $-5.6090^{* * *}$ & $-3.7796^{* * *}$ & $-0.1308^{* *}$ & $-3.3393^{* * *}$ \\
\hline & $(39.35)$ & $(18.90)$ & $(28.04)$ & $(19.56)$ & $(2.20)$ & $(22.69)$ \\
\hline \multicolumn{7}{|l|}{ Technical inefficiency } \\
\hline \multirow[t]{2}{*}{ Log farm size } & -0.5181 & $-1.5376^{* *}$ & $-2.6003^{* * *}$ & -0.4776 & -0.8335 & -0.8335 \\
\hline & $(0.82)$ & $(2.50)$ & (3.09) & $(0.13)$ & $(0.18)$ & $(0.18)$ \\
\hline \multirow[t]{2}{*}{ Time } & -0.0313 & $-0.0289^{* *}$ & $-0.1869^{* * *}$ & 0.0401 & -0.2768 & -0.2768 \\
\hline & $(1.30)$ & $(2.00)$ & $(5.91)$ & $(0.41)$ & $(1.04)$ & $(1.04)$ \\
\hline \multirow[t]{2}{*}{ Constant } & $-1.8596^{* *}$ & -0.5552 & 1.0355 & -2.8774 & -9.5017 & -1.6401 \\
\hline & (2.03) & $(0.67)$ & $(0.89)$ & $(0.36)$ & $(0.74)$ & $(0.44)$ \\
\hline Province dummy & yes & yes & yes & yes & yes & yes \\
\hline Wald $\operatorname{chi}^{2}(13)$ & $4.55 \mathrm{e}+06$ & $3.90 \mathrm{e}+06$ & $6.09 \mathrm{e}+06$ & $1.16 \mathrm{e}+06$ & $9.93 \mathrm{e}+06$ & $1.24 \mathrm{e}+06$ \\
\hline Log likelihood & 376.968 & 319.371 & 354.080 & 91.055 & 102.7383 & 47.065 \\
\hline No. of obs & 625 & 596 & 439 & 406 & 430 & 456 \\
\hline
\end{tabular}

Note: Absolute $t$ statistics in parentheses; ${ }^{*} P<0.10, * * P<0.05, * * * P<0.01$.

a linear time trend to capture technological progress, and $\beta$ is the associated vector of technology parameters to be estimated. Thus, $v_{i t}$ represents a random error term with $v_{i t} \sim N\left(0, \sigma_{v}\right)$, and $\mu_{i t}$ is the technical inefficiency with $u_{i t} \sim N^{+}\left(0, \sigma_{u}\right)$.

This technical inefficiency term $u_{i t}$ is allowed to be heteroskedastic by introducing a multiplicative relationship between the variables in $f\left(X_{i t}, T ; \beta\right)$ responsible for heteroskedasticity and the common distribution parameter $\sigma_{u}$. In particular, we hypothesize that technical inefficiency is related to farm size ( $\ln S_{i t}$ ) following the literature. ${ }^{7}$

\footnotetext{
${ }^{7}$ Note that farm size is the province-level average, not separately calculated for each commodity. Thus, this setting creates measurement errors in the farm size data when estimating commodity-wise production functions. Besides, as we discussed earlier, the data are possibly underestimated in provinces where
}

We calculate TFP, technical change, technical efficiency, and output elasticities (e.g., Kumbhakar et al., 2000; del Valle et al., 2003). The calculations of TFP, technical change, and technical efficiency follow the formulas shown in Kumbhakar et al. (2000). Kumbhakar et al. (2000) decomposed TFP into scale effect, technical change, technical efficiency change, and the input price allocative effect. Since the unit of observations in

nonagricultural works are easily available in rural areas and a portion of farmers are engaged in cultivations. The reported farm size is the true size multiplied by a factor specific to province, that is, $S_{i t}=S_{i t}{ }^{*} \varphi_{i}$ where $\varphi_{i}$ is the ratio of the actual farm population to the registered farm population. Log transformation separates $\ln \varphi_{i}$, which will be controlled by province fixed effects in the technical inefficiency term. 
Decomposition of TFP and output and substitution elasticities by crops, 1984-2012

\begin{tabular}{|c|c|c|c|c|c|c|c|}
\hline & \multirow[b]{2}{*}{$\mathrm{TFP}^{*}$} & \multirow[b]{2}{*}{$\mathrm{TC}^{*}$} & \multirow[b]{2}{*}{$\mathrm{TEC}^{*}$} & \multicolumn{3}{|c|}{ Elasticity } & \multirow{2}{*}{$\begin{array}{l}\text { Morishima } \\
\text { elasticity of } \\
\text { substitution } \\
\text { Labor-machine }\end{array}$} \\
\hline & & & & Labor & Machine & Fertilizer & \\
\hline Wheat & 0.856 & 0.830 & 0.052 & 0.360 & 0.400 & 0.191 & 0.10 \\
\hline Corn & 2.877 & 2.558 & 0.311 & 0.444 & 0.103 & 0.155 & 0.34 \\
\hline Japonica rice & 1.326 & 0.614 & 0.708 & 0.414 & 0.175 & 0.243 & 0.98 \\
\hline Soybean & 0.749 & 1.251 & -0.506 & 0.521 & 0.203 & 0.242 & 0.35 \\
\hline Cotton & 2.391 & 2.467 & -0.074 & 0.316 & 0.193 & 0.323 & 0.64 \\
\hline Rapeseeds & 3.099 & 2.487 & 0.645 & 0.489 & 0.145 & 0.318 & 0.33 \\
\hline
\end{tabular}

*Values represent the annual growth rate of TFP, TC, and TEC.

the analysis is province, we do not derive the scale effect. ${ }^{8}$ The input price allocative effects cannot be also derived due to the limitation of input price data. Thus, we decompose TFP into two components-technical change and technical efficiency.

Morishima elasticity of substitution (MES) between labor and machines is calculated from the translog production estimates. MES measures the percentage change in the ratio of input $i$ to input $j$ when the price of input $j$ alone varies proportionately and all other prices are constant (Blackorby and Russell, 1989; Sharma, 2002). This can be generalized into an expression of a Hicksian two-inputs elasticity of a multifactor setting as follows:

$\sigma_{i j}=\frac{f_{i}}{x_{j}} \frac{H_{i j}}{|H|}-\frac{f_{i}}{x_{i}} \frac{H_{i i}}{|H|} i \neq j$,

where $H_{i j}$ and $H_{i i}$ represents the cofactors of the Hessian $(H)$ with respect to $(i, j)$ and $(i, i)$, respectively; $|H|$ is the determinant of the bordered Hessian, $f_{i}=\frac{\partial \ln Y}{\partial \ln x_{i}} \frac{x_{i}}{Y}$ (marginal product) $f_{i i}=$ $\frac{\partial f_{i}}{\partial x_{i}}$ and $^{\prime} f_{i i}=\frac{\partial f_{i}}{\partial x_{i}}$. Note that, by its construct, MES is the crossprice elasticity (the first term in Eq. (4)) minus the own price elasticity (the second term in Eq. (4)), thus it is not symmetric. In the context where an increase in wage is the main factor that is considered to induce the substitution of labor and machines, we let $i$ and $j$ represent labor and machine, respectively.

\section{Empirical results}

Table 2 reports estimates of the production frontier function with both province and year fixed effects. Province fixed effects control for all time-invariant differences between provinces. Year fixed effects control for time-variant changes that affect all provinces similarly. With parameters constrained to exhibit constant returns to scale, estimates look fairly theory consistent.

The parameter estimates are basically within reasonable ranges and therefore interpretable, though we have to calcu-

\footnotetext{
${ }^{8}$ In fact, traditionally in Asian agriculture heavily relying on cropping systems with small landholdings, scale effects are generally not very important (Otsuka et al., 2014).
}

late input as well as substitution elasticities to derive a remark on our main hypothesis. That is, a rapid change in the relative price of labor and machines observed in recent years has driven the substitution of labor by machines. The technical inefficiency function shows that, the average farm size increases the overall technical efficiency. The negative marginal effect associated with the average farm size means that an increase in farm size reduces technical inefficiency, that is, the distance from the frontier becomes smaller. This is consistent with the proportion that small farm size is one of the major constraints hindering mechanization, but does not necessarily exclude the possibility that a large change in the relative price induces the substitution between labor and machines. In China, it appears likely that the emergence of machine rental services mitigates the constraints on small holders when the machine-labor relative price rapidly changes.

Table 3 shows the calculated the annual growth rate of TFP, technical change and technical efficiency, output elasticities, and the Morishima Elasticity of Substitution between labor and machines over 1984-2012. First, we report that corn, cotton, and rapeseeds experienced relatively large TFP, followed by Japonica rice. In the first three crops, the large TFP is attributed to a large contribution of technical change, while TEC grows moderately in corn and rapeseeds. Second, output elasticity estimates show that labor has the largest elasticity in all commodities, except wheat. The output elasticities of fertilizer and machines vary across crops reflecting the agronomic traits of crops.

Third, we observe a large substitution between labor and machines in Japonica rice production, followed by cotton. This could be explained as rice and cotton are more labor-intensive than the other crops. When the wage has risen, the farmers are more likely to use machines to substitute for labor in the production largely through machine services and/or rental. The MES ranges around $0.33-0.35$ for soybean, corn, and rapeseeds. The labor-machine substitution is relatively small in these crops wheat. The results are consistent with our observations in Fig. $2 .{ }^{9}$

\footnotetext{
${ }^{9}$ The estimates are statistically significant at the conventional level (1\%).
} 
Based on the above results, we may conclude that (i) the relative price of machines against agricultural labor is the main driving force to promote mechanization, especially in recent years when agricultural wages increased in an accelerating way, (ii) the substitution of labor by machines seems to be rather smooth as well, which supports the use of machines in agricultural production. The results are consistent with the findings of Wang et al. (2014) that there seem to be ways to bypass or mitigate constraints related to small farm size such as through land rental markets, land consolidation, machine rental, and providers.

\section{Conclusions}

In this article, we used commodity-wise province-level panel data to investigate major factors that explain fast mechanization and the substitution between labor and machines through estimating frontier production functions. The analysis demonstrated a dramatic increase in real agricultural wages in recent years (especially, after 2003) in contrast to a relatively stable real machine price. The relative price of machines to agricultural labor has declined in an accelerating way, which contributed to the observed rapid introduction of machines (or use of machine services). Our estimates of the elasticity of substitution between labor and machines (based on the production frontier function estimates) demonstrate that such an effect is strong in wheat, rapeseeds, soybean productions. Even in the case of weak substitutions (the elasticity being near or less than one), a large increase in real agricultural wages has induced the capital-labor substitution to some extent in all commodities considered.

While rising wages will be good for poverty alleviation and will contribute to higher welfare in large segments of the rural population, they will also lead to challenges in agricultural sector (Wang et al., 2011). To face the challenges, Chinese smallholders adopted mechanization (Ji et al., 2012; Wang et al., 2014), and now mechanical operations are widely observed in agricultural production, especially grain production throughout China. Technological change including the adoption of mechanical operations can likely account for a significant part of total factor productivity.

\section{Acknowledgments}

We acknowledge the funding from National Natural Sciences of China (71373255; 71333013), the Institute of Geographic Sciences and Natural Resources Research, CAS (2012RC102; 2012ZD208) and Chinese Academy of Sciences (KSZD-EWZ-021-1; Y02015004).

\section{References}

Battese, G.E., Coelli, T.J., 1992. Frontier production functions, technical efficiency and panel data: With application to paddy farmers in India. J. Prod. Anal. 3, 153-169.

Blackorby, C., Russell, R R., 1989. Will the real elasticity of substitution please stand up?: A comparison of the allen/uzawa and morishima elasticities. Am. Econ. Rev. 79(4), 882-888.

Cook, S., 1999. Surplus babour and productivity in Chinese agriculture: Evidence from household survey data. J. Dev. Stud. 35, 16-44.

Del Valle, I., Astorkiza, I., Astorkiza, K., 2003. Fishing effort validation and substitution possibilities among components: The case study of the VIII division European anchovy fishery. Appl. Econ. 35, 63-77.

Hayami, Y., Ruttan, V.W., 1985. Agricultural development: An international perspective. The Johns Hopkins University Press, Baltimore.

Hicks, J.R., 1932. The theory of wages. Macmillan, London.

Huang, J., Rozelle, S., 1996. Technological change: The re-discovery of the engine of productivity growth in China's rice economy. J. Dev. Econ. 49, 337-369.

Huang, J., Rozelle, S., Rosegrant, M., 1999. China's food economy to the 21st century: Supply, demand, and trade. Econ. Dev. Cult. Change. 47, 737-766.

Ji, J., Yu, X., Zhong, F., 2012. Machinery investment decision and off-farm employment in rural China. Ch. Econ. Rev. 23, 71-80.

Jin, S., Huang, J., Hu, R., Rozelle, S., 2002. The creation and spread of technology and total factor productivity in China's agriculture. Am. J. Agric. Econ. 84, 916-930.

Jin, S., Ma, H. Huang, J., Hu, R., Rozelle, S., 2010. Productivity, efficiency and technical change: Measuring the performance of China's transforming agriculture. J. Prod. Anal. 33, 191-207.

Kumbhakar, S., Denny, M., Fuss, M., 2000. Estimation and decomposition of productivity change when production is not efficient: A panel data approach. Econometric Rev. 19, 312-320.

Lin, J.Y., 1992. Rural reforms and agricultural growth in China. Am. Econ. Rev. 82(1), 34-51

National Statistical Bureau, China (NSBC), 2014. China's statistical yearbook. China's Statistical Press, various issues. Beijing, China.

National Statistical Bureau, China (NSBC), 1985-2013. China yearbook of rural household survey. China's Statistical Press, various issues. Beijing, China.

Otsuka, K., Liu Y., Yamauchi, F., 2013. Factor endowments, wage growth, and changing food self-sufficiency: Evidence from country-Level panel data. Am. J. Agric. Econ. 95, 1252-1258.

Rae, N., Ma, H., Huang, J., Rozelle, S., 2006. Livestock in China: commodityspecific total factor productivity decomposition using new panel data. Am. J. Agric. Econ. 88(3), 680-695.

Sharma, S., 2002. The Morishima elasticity of substitution for the variable profit function and the demand for imports in the United States. Intern. Econ. Rev. 43(1), 115-135.

State Price Bureau, 1985-2013. The compiled materials of costs and profits of agricultural products of China, China Price Bureau Press, Beijing.

Wang, X., Huang, J., Zhang, L., Rozelle, S., 2011. The rise of migration and the fall of self employment in rural China's labor market. Chin. Econ. Rev., 22, 573-584.

Wang, X., Yamauchi, F., Otsuka, K., Huang, J., 2014. Wage growth, landholding and mechanization in Chinese agriculture, Manuscript, Center for Chinese Agricultural Policy, World Bank, and National Graduate Institute for Policy Studies.

Yang, J., Huang, Z., Zhang, X., Reardon, T., 2013. The rapid rise of crossregional agricultural mechanization services in China. Am. J. Agri. Econ. 95(5), 1245-1251. 